\title{
Notable intrafamilial phenotypic variability in a kindred with familial adenomatous polyposis and an $A P C$ mutation in exon 9
}

\author{
P Rozen, Z Samuel, R Shomrat, C Legum
}

\begin{abstract}
Background-The phenotypic spectrum of familial adenomatous polyposis (FAP) varies from the classic appearance of hundreds of adenomatous colonic polyps in the young adult and early onset colorectal cancer, to the occurrence of sparse adenomas in the older adult, "attenuated" FAP, due to mutations at the $5^{\prime}$ or $3^{\prime}$ ends of the $A P C$ gene.

Aims-To investigate marked intrafamilial phenotypic variation occurring in a family with an $A P C$ gene mutation in exon 9.

Patients-An extended kindred of 22 people of whom 16 had colorectal neoplasia and/or were $A P C$ mutation carriers.

Results-Phenotypic manifestation varied from classic FAP to a complete lack of clinical or endoscopic, or bioptic disease in five people in three different generations. This occurred in four of them over two generations, in spite of having a confirmed $11 \mathrm{bp}$ insertion causing a frame shift and stop codon (363) in exon 9 of the $A P C$ gene.

Conclusions-At present, it is assumed that in this family there is alternative splicing of the $A P C$ gene, and/or unidentified modifying genetic factors. The family illustrates the importance of genetic testing in evaluating carrier status and not just clinical examination. This clinical observation also highlights the dilemma in recognising the possible contribution of low penetrance germline $A P C$ mutations to what has been considered "sporadic" colorectal neoplasia.

(Gut 1999;45:829-833)
\end{abstract}

Gastroenterology, Tel

Aviv Medical Centre, 6

Weizmann Street, Tel

Aviv 64239, Israel

P Rozen

Z Samuel

Department of Genetics, Tel Aviv

Medical Centre, 6

Weizmann Street, Tel

Aviv 64239, Israel

R Shomrat

C Legum

Correspondence to:

Professor Rozen

Accepted for publication 2 June 1999 by linkage and now by direct mutation analysis, a minimal clinical form of disease, "attenuated" FAP, has been recognised. ${ }^{2-4}$ Even when the most definitive clinical expression of FAP, namely multiple adenomatous colonic polyps is absent in the postadolescent, histological changes such as depressed adenomas or even intramucosal adenomas can be shown, suggesting carrier status. ${ }^{5-7}$

As direct genetic testing became more routine, it was found that the same $A P C$ mutation could cause different clinical manifestations in different families ("interfamilial" phenotypic variation).$^{8-10}$ Clinically, the picture has been further confused by the finding of "intrafamilial" variability of disease expression. ${ }^{19-17}$ This led to the hypothesis that there are genetic-environmental interactions and/or that there may be "modifying" genes in certain families, as has been found in animal models. ${ }^{1} 101118$

Because of the clinical features consistent with high penetrance of the $A P C$ mutation, it has been calculated that in the absence of clinical features by the age of 40 years, there was a high probability (almost $100 \%$ ) of noncarrier status. ${ }^{19}$ Hence, such an individual and his or her descendants would be regarded as disease-free. We present an extended FAP kindred that illustrates the clinical dilemmas that could face the physician as a result of extreme intrafamilial phenotypic variability of disease expression.

\section{Clinical data}

Figure 1 shows the family K pedigree (FAP 11). The propositus (III.3) was a 56 year old nurse who was diagnosed as having metastatic colorectal cancer on the background of multiple (more than 100) colonic adenomatous polyps. Because of the clinical diagnosis of FAP, genetic testing for the $A P C$ mutation was done after obtaining informed consent. Further antecedent family clinical details were obtained from her and from her siblings, but were not verifiable. Her father (II.2) had died from "old age" at the age of 82 years. He never had a history of colonic or neoplastic diseases. His own siblings (II.4, II.5, II.6, II.7) and father (I.1) died at the ages of 50-76 years from colorectal or non-colonic cancer; they were not known to have colonic polyps. The mother of the propositus, who was her husband's first cousin, committed suicide at the age of 40 years. Neither she nor her immediate family had a history of colonic or neoplastic disease.

The siblings (III.6, III.7) and daughter (IV.6) of the propositus were asymptomatic
Abbreviations used in this paper: FAP, familial adenomatous polyposis; CHRPE, congenital hypertrophy of the retinal pigment epithelium. 
II

III IV

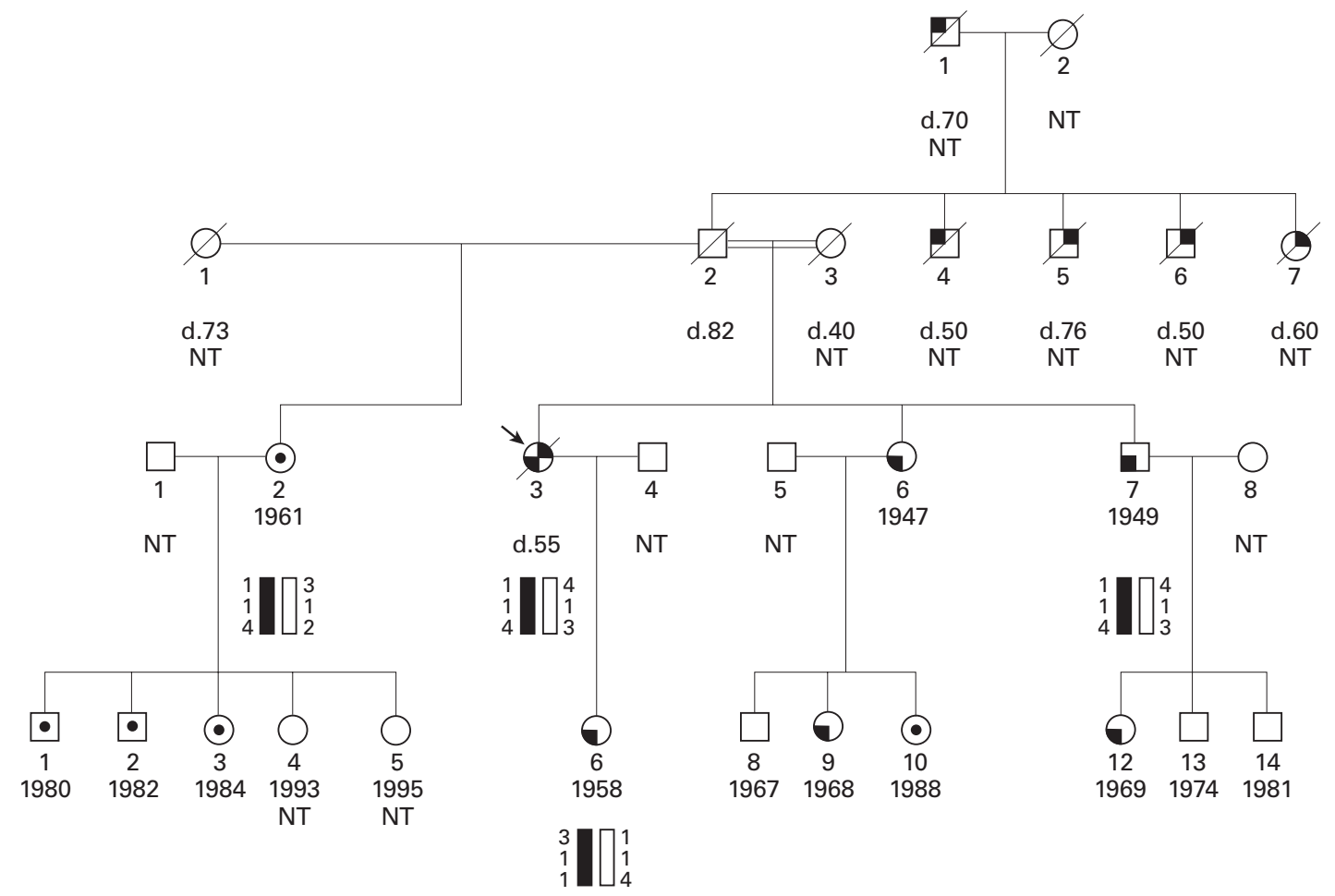

Markers alleles

YN5.64 CA 1..8

CB83 CA1 1..12

DPICA $1 . .12$

Symbol definitions

$\square \bigcirc$ Not carrier or tested (NT)

- Carrier

$\square \bigcirc$ Colorectal cancer (CRC)

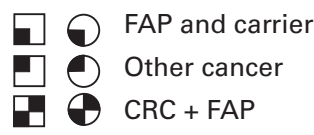

Figure 1 Family K pedigree. Note the common alleles of III.2, III.3, III.7, and IV.6 assumed to be from their common II. 2 origin (black bar). The second allele of III. 2 is dissimilar to those of III. 3 and III. 7 and is therefore assumed to be from their different mothers (blank bar). NT, not tested for APC mutation; d, died (age in years); arrow, propositus.

and invited for clinical examination and genetic testing. Because of the presence of numerous adenomatous colonic polyps $(>100$ in IV.6 and 30-40 in III.6) and their ages (36 and 50 years), they were advised to have definitive preventive colonic surgery. Patient III.7, aged 48 years, who was completely asymptomatic and had 40-50 colonic adenomas, but no rectal polyps, elected to have an ileorectal anastomosis; the other two had an ileoanal pouch formed with rectal mucosal stripping. Preoperative and postoperative upper endoscopy, using both a side viewing duodenscope and forward viewing gastroscope and taking random biopsy samples, did not show the presence of duodenal adenomatous polyps or fundic gland polyps in any of these three cases. Because of recurrent abdominal pain and the clinical diagnosis of intraabdominal desmoid, patient III. 6 has been prescribed sulindac. Patient IV. 6 had been treated for thyrotoxicosis, has subcutaneous nodules on her hands, and postoperative computed tomography (CT) findings are suggestive of an abdominal desmoid but no treatment has been required. Patient IV.9 and IV.12 had their first colonoscopies at ages 31 and 30 years respectively and were each found to have 10 adenomas sized $2 \mathrm{~mm}$ and IV.12 also had one of $0.5 \mathrm{~cm}$. They have postponed elective colectomy. In all five patients there was rectal sparing and the polyps were found scattered throughout the colon. IV.10, aged 15 years, has had her first endoscopic examination; no polyps were detected and micro-adenomas were not evident on multiple random biopsy samples. Neither of the two affected children of III.6 have clinical evidence of osteomata and were not examined for congenital hypertrophy of the retinal pigment epithelium (CHRPE). The father (II.2) of the propositus remarried. His new daughter (III.2; half sister to the propositus and having the same $A P C$ mutation) had no specific colonic symptoms, but complained of abdominal discomfort and was known to have mild chronic anaemia. She was examined by flexible sigmoidoscopy and twice by colonoscopy; no polyps were identified by the age of 38 years. Fifteen random biopsy specimens were taken systematically throughout the colon and no intramucosal adenomas or histological perturbations were 
Table 1 Neoplasia in family K (FAP 11), as reported or found at endoscopy

\begin{tabular}{|c|c|c|c|}
\hline & Pedigree position & Age (y) & No of polyps/cancer \\
\hline Propositus ${ }^{\star}$ & III. 3 & 56 & $>100 /$ CRC \\
\hline Grandfather (paternal) $\dagger$ & I. 1 & 70 & Cancer \\
\hline Fathert & II. 2 & 82 & Unknown \\
\hline Uncle (paternal)† & II. 4 & 50 & "Bone" cancer \\
\hline Uncle (paternal) $†$ & II. 5 & 76 & CRC \\
\hline Uncle (paternal) $†$ & II. 6 & 50 & CRC \\
\hline Aunt (paternal) $\dagger$ & II. 7 & 60 & CRC \\
\hline Sister ${ }^{\star}$ & III. 6 & 50 & $30-40$ \\
\hline Brother* & III. 7 & 48 & $40-50$ \\
\hline Daughter* & IV.6 & 36 & $>100$ \\
\hline $\mathrm{Niece}^{\star}$ & IV.9 & 31 & 10 \\
\hline $\mathrm{Niece}^{\star}$ & IV. 10 & 15 & None \\
\hline $\mathrm{Niece}^{\star}$ & IV.12 & 30 & 10 \\
\hline Half-sister ${ }^{\star}$ & III. 2 & 38 & None \\
\hline Half-nephew ${ }^{\star}$ & IV.1 & 17 & None \\
\hline Half-nephew ${ }^{\star}$ & IV.2 & 15 & None \\
\hline Half-niece ${ }^{\star}$ & IV.3 & 13 & None \\
\hline
\end{tabular}

${ }^{\star}$ Confirmed mutation carriers examined by endoscopy. $†$ Clinical data obtained by history. There were no reports of colonic polyps.

CRC, colorectal cancer.
FAP, has now agreed to be tested. Because of the unexpected positive genetic evidence of mutation carrier status without evidence of disease, fresh DNA samples were again taken from III.2 and retested, confirming the previous results. Analysis for the $11307 \mathrm{~K}$ APC variant is routine and was negative in this family. ${ }^{20}$

Three microsatellite markers flanking the $A P C$ gene (YN5.64 and CB83 proximal and DP1 distal to the gene) were examined on all available direct descendants of the father, II.2 (fig 1). Common alleles were found in all his descendants (III.2, III.3, III.7, and IV.6), and so are presumed to be of the same paternal origin. The second allele of III. 2 is different from those of her half siblings III. 3 and III. 7 and is assumed to represent their different maternal origins (fig 1).

detected. Upper endoscopy was performed three times and again no polyps were seen or found in random biopsy specimens taken from the duodenum and stomach. Unexpectedly, subtotal villous atrophy was repeatedly found and the patient has been on a gluten-free diet for the past two years. Her abdominal symptoms and anaemia have disappeared and on rebiopsy, minimal remnants of treated coeliac disease were found in the small bowel mucosa. Her three oldest, postadolescent children (IV.1, IV.2, IV.3) were found to be carriers of the same mutation as their mother and the propositus (III.2). All three children were examined clinically and have no evidence of osteomata or soft tissue lesions. They are negative for CHRPE and skull $x$ rays of IV. 1 did not show osteomata. Endoscopically, no adenomas or evidence of intramucosal disease were detected.

Table 1 summarises the neoplasia of the kindred. All available histology sections have been reviewed personally and the findings confirmed. As seen from the pedigree of this kindred, expression of the mutation may well be age dependent. The mutation carriers in this family will therefore remain under yearly observation; colonoscopic examinations with multiple directed and random biopsies will be performed every one to two years.

\section{Genetic testing}

Following consultation, genetic testing was performed on the propositus and subsequently on her first degree relatives, using both linkage and direct mutation analyses. Germline mutation analysis was performed using the protein truncation test for exon 15, and single strand conformation polymorphism screening for other exons. This was followed by sequencing using the $\mathrm{ABI} 310$ sequencer.

An $11 \mathrm{bp}$ insertion (AAGGATGATAT) was identified in exon 9 at nucleotide 1060 (codon 353). This caused a frame shift and premature termination downstream at nucleotide 1088 (codon 363). This mutation was found in all four children of II.2 and grandchildren as listed in table 1 and shown in fig 1. Predictive genetic testing is not offered to the preadolescent children and IV.8, at risk for

\section{Discussion}

Mutations causing the clinical features of FAP have been found throughout the $A P C$ gene on chromosome 5 . There have been correlations made between the different mutation types, their sites, and the phenotypic manifestations. ${ }^{12} 141517$ 21-23 However, there can be notable variation in intrafamilial phenotype. ${ }^{9-17}$ As recently discussed in an editorial by Lynch and Smyrk, this spectrum of phenotypic manifestations is "a diagnostic nightmare". ${ }^{24}$ It has both diagnostic and therapeutic implications and the contribution of FAP mutations to "sporadic" colorectal cancer needs to be evaluated. ${ }^{24}$ Even so, in the published series (except in families reported by Evans and colleagues ${ }^{9}$ ), there were at least some minimal clinical manifestations of FAP in every adult carrier of $A P C$ mutations, in spite of the phenotypic variability. In our kindred, there was not only notable intrafamilial variability of FAP phenotype (numbers of adenomas, age of onset of cancer), but in one branch a lack of FAP clinical manifestations extending over three generations. In this one family branch there is also no macroscopic or microscopic evidence of disease in two generations in spite of being carriers of the same $A P C$ mutation as the clinically affected relatives.

Van der Luijt et al described a family with a frame shift mutation located in an alternative splicing region of exon 9 with intrafamilial phenotypic variability (numbers of polyps and late onset of colorectal cancer); one family member, aged 18 years, was reported to be free of polyps. ${ }^{25}$ In the recent series on attenuated FAP, published by Soravia et al, two kindreds with different mutations within exon 9, but outside the alternative splicing region were described. ${ }^{16}$ Clinically, these two kindreds showed notable intrafamilial variability in expression of colorectal cancer and/or adenoma; it was suggested that mutations in exon 9 may result in a less severe phenotype. White et al described a cancer prone family having a germline $A P C$ mutation $\left(\mathrm{G} 1 \mathrm{n}^{1317}\right)$, but without the phenotypic features of FAP. ${ }^{26}$ That family had a missense mutation, which did not result in truncation of the $A P C$ 
protein. Frayling et al also identified the E1317Q missense $A P C$ variant in British patients with multiple colorectal adenomas or cancer, but not necessarily having such a family history. ${ }^{27}$

In our family, there was a large $11 \mathrm{bp}$ insertion, causing a frame shift and premature stop codon, which would be expected to change the function of the protein product. At present, we do not have an explanation for the variability of the FAP phenotype and even its total absence in one family branch having the same mutation. Theoretically, the mutation terminates translation before the alternative splice site, but it has been postulated previously that mutations in the vicinity of the alternatively spliced region of exon 9, 9A, may be excised by the alternative splice, resulting in the production of a shorter protein which is sufficiently functional to prevent polyp production almost completely, at least in some individuals. ${ }^{28}{ }^{29} \mathrm{We}$ have not yet examined this hypothesis in our family.

It may be of importance that the branch of our family with the most prominent features of FAP are the descendants of parents who were cousins. The half sibling and her family, having a different mother, may have inherited a modifying protective gene that inhibits manifestation of FAP. In the Min mouse model of FAP, the phenotypic manifestation of disease does not entirely mimic human FAP and modifying locus Mom1 was identified on mouse chromosome $4 .{ }^{18}{ }^{30}$ The equivalent site in humans is on chromosome 1 and the candidate modifying locus is secretory phospholipase A2. ${ }^{30}$ However, when examining the possibility that this is the site of a modifying locus in human clinical material and tissues, it could not be confirmed..$^{30-32}$ Another mouse FAP model $A p c^{4716}$ that had disruption of the $C O X-2$ locus showed a dramatic decrease in intestinal polyps. Sequencing the equivalent $C O X-2$ area in patients with FAP did not show significant perturbations in those with or without multiple polyps. ${ }^{33}$ Other modifying genes are therefore being searched for, based on discordant sibpairs (Dr I Tomlinson, personal communication). Clearly, environmental factors can also play a role, as shown by the known influence of nonsteroidal anti-inflammatory drugs and even dietary intervention in suppressing polyp growth. ${ }^{102433}$

The clinical implications of our family and those presented in a recent review ${ }^{24}$ are important. It seems that the absence of macroscopic and even microscopic evidence of familial adenomatous polyposis, even in mature adults, does not preclude $A P C$ mutation carrier status. If we had not performed mutation analysis, we would not have identified III.2 and her descendants as being mutation carriers and they would not now be under surveillance. The clinical appearance of $\mathrm{FAP}$, at a later age and/or in some future generation, would then mistakenly be called a "spontaneous" mutation or sporadic neoplasia.
In conclusion, family $\mathrm{K}$ illustrates both the variable intrafamilial phenotypic manifestations of FAP and also a complete absence of clinical disease in spite of positive $A P C$ mutation carrier status. The implications are that genetic testing of asymptomatic first degree relatives of patients with FAP is essential, even in the absence of clinical disease in adulthood. The biological explanations for this variability need to be evaluated and may have important aetiological and therapeutic implications for what has been regarded as "sporadic" colorectal cancer.

We thank the family members for their cooperation and Dr I Tomlinson, London, for his advice. The Israel Cancer Association supports the Consultative Service for Hereditary Cancer in the Gastroenterology Department.

1 Howe JR, Guillem JG. The genetics of colorectal cancer. Surg Clin North Am 1997;77:175-95.

2 Lynch HT, Smyrk T, McGinn T, et al. Attenuated familial adenomatous polyposis (AFAP). Cancer 1995;76:2427-33.

3 Spirio L, Olschwang S, Groden J, et al. Alleles of the APC gene: an attenuated form of familial polyposis. Cell 1973;75:951-7.

4 Friedl W, Meuschel S, Caspari R, et al. Attenuated familial adenomatous polyposis due to a mutation of the 3' part of
the APC gene. A clue for understanding the function of the APC protein. Hum Genet 1996;97:579-84.

5 Newbold KM, Warfield AT, MacDonald F. Undifferentiated columnar cells in colorectal adenomas and familial adenomatous polyposis. F Pathol 1989;158:93-6.

matous polyposis. F Pathol 1989;158:93-6.
6 Bradburn DM, Gunn A, Hastings A, et al. Histological detection of microadenomas in the diagnosis of familial detection of microadenomas in the diagnosis of fam

7 Kubota O, Kino I. Depressed adenomas of the colon in Kubota O, Kino I. Depressed adenomas of the colon in
familial adenomatous polyposis. Am f Surg Pathol 1995;19: $318-27$

8 Paul P, Letteboer T, Gelbert L, et al. Identical APC exon 15 mutations result in a variable phenotype in familial adenomatous polyposis. Hum Mol Genet 1993;2:925-31.

9 Evans DGR, Guy SP, Thakker N, et al. Non-penetrance and late appearance of polyps in families with familial adenomatous polyposis. Gut 1993;34:1389-93.

10 Giardiello FM, Krush AJ, Petersen GM, et al. Phenotypic variability of familial adenomatous polyposis in 11 unrelated families with identical APC gene mutation. Gastroenterology 1994;106:1542-7.

11 Scott RJ, van der Luijt R, Spycher M, et al. Novel germline APC gene mutation in a large familial adenomatous polyposis kindred displaying variable phenotypes. Gut polyposis kindred

12 Lynch HT, Lynch PM, Follett KL, et al. Familial polyposis coli: heterogeneous polyp expression in 2 kindreds. $\mathcal{F}$ Med Genet $1979 \cdot 16: 1-7$

13 Presciuttini S, Varesco L, Sala P, et al. Age of onset in familial adenomatous polyposis: heterogeneity within families and among APC mutations. Ann Hum Genet 1994;58:33142 .

14 Bunyan DJ, Shea-Simonds J, Reck AC, et al. Genotypephenotype correlations of new causative APC gene mutations in patients with familial adenomatous polypsis. $\mathcal{F}$ Med Genet 1995;32:728-31.

15 Walon C, Kartheuser A, Michills G, et al. Novel germline mutations in the APC gene and their phenotypic spectrum in familial adenomatous polyposis kindreds. Hum Genet 1997;100:601-5.

16 Soravia C, Berk T, Madlensky L, et al. Genotype-phenotype correlations in attenuated adenomatous polyposis coli. Am f Hum Genet 1998;62:1290-301.

17 Brensinger JD, Laken SJ, Luce MC, et al. Variable phenotype of familial adenomatous polyposis in pedigrees phenotype of familial adenomatous polyposis in pedigree
with 3' mutation in the APC gene. Gut 1998;43:548-52.

18 Shoemaker AR, Gould KA, Luongo C, et al. Studies of neoplasia in the Min mouse. Biochim Biophys Acta 1997;1332:
. F25-48.

19 Bisgaard ML, Fenger K, Bulow S, et al. Familial adenomatous polyposis (FAP): frequency, penetrance, and mutation rate. Hum Mutat 1994;3:121-5

20 Rozen P, Shomrat R, Strul H, et al. Prevalence of the I1307K APC gene variant in Israeli Jews of differing ethnic origin and risk for colorectal cancer. Gastroenterology 1999; 116:54-7.

21 Nagase H, Miyoshi Y, Horii A, et al. Correlation between the location of germ-line mutations in the APC gene and the number of colorectal polyps in familial adenomatous polyposis patients. Cancer Res 1992;52:4055-7.

22 Caspari R, Friedl W, Mandl M, et al. Familial adenomatous polyposis: mutation at codon 1309 and early onset of colon polyposis: mutation at codon 1309

23 Dobbie Z, Spycher M, Mary J-L, et al. Correlation between the development of extracolonic manifestations in FAP patients and mutations beyond codon 1403 in the APC gene. $\mathcal{F}$ Med Genet 1996;33:274-80. 
24 Lynch HT, Smyrk TC. Classification of familial adenomatous polyposis: a diagnostic nightmare. Am $\mathcal{F}$ Hum Genet tous polyposis: a
1998;62:1288-9.

25 van de Luijt RB, Vasen HFA, Tops CMJ, et al. APC mutation in the alternatively spliced region of exon 9 associated with late onset familial adenomatous polyposis. Hum Genet 1995;96:705-10.

26 White S, Bubb VJ, Wyllie AH. Germline APC mutation $\left(\mathrm{G} 1 \mathrm{n}^{1317}\right)$ in a cancer-prone family that does not result in familial adenomatous polyposis. Genes Chromosom Cancer 1996;15:122-8. 27 Frayling IM, Beck NE, Ilyas M, et al. The APC variants
I1307K and E1317Q are associated with colorectal tumors, but not always with a family history. Proc Natl Acad Sci USA 1998;95:10722-7.

28 Young J, Simms LA, Tarish J, et al. A family with attenuated familial adenomatous polyposis due to a mutation in the familial adenomatous polyposis due to a mutation in the 1998;11:450-5.
29 Santoro IM, Groden J. Alternative splicing of the APC gene and its association with terminal differentiation. Cancer Res 1997;57:488-94.

30 Dove WF, Cormier RT, Gould KA, et al. The intestinal epithelium and its neoplasms: genetic, cellular and issue interactions. Phil Trans R Soc Lond B 1998;353:915-23.

31 Tomlinson IPM, Beck NE, Neale K, et al. Variants at the secretory phospholipase A2 (PLA2G2A) locus: analysis of associations with familial adenomatous polyposis and sporadic colorectal tumours. Ann Hum Genet 1996;60:369-76.

32 Praml C, Amler LC, Dihlmann S, et al. Secretory type II phospholipase $A_{2}$ (PLA2G2A) expression status in colorectal carcinoma derived cell lines and in normal colonic mucosa. Oncogene 1998;17:2009-12.

33 Spirio LN, Dixon DA, Robertson J, et al. The inducible prostaglandin biosynthetic enzyme, cyclooxygenase 2 , is a not mutated in patients with attenuated adenomatous polyposis coli. Cancer Res 1998;58:4909-12. 